\title{
Cat-scratch Disease with Parinaud's Oculoglandular Syndrome
}

\author{
Case Report \\ Ana Sousa Menezes (D), Daniela Ribeiro (D), António Fontes Lima (D) \\ Department of Otorhinolaryngology - Head and Neck Surgery, Hospital de Braga, Braga, Portugal
}

Abstract

ORCID IDs of the authors: A.S.M. 0000-0001-5099-3811; D.R. 0000-0002-8464-9653;

A.F.L. 0000-0001-9888-9394.

Cite this article as: Sousa Menezes $A$, Ribeiro D, Fontes Lima A. Cat-scratch disease with Parinaud's oculoglandular syndrome. Turk Arch Otorhinolaryngol 2020; 58(1): 48-51.

\section{Corresponding Author:}

Ana Sousa Menezes; ana4644@gmail.com

Received Date: 21.09.2019

Accepted Date: 04.12.2019

Available Online Date: 26.03 .2020

Content of this journal is licensed under a Creative Commons Attribution 4.0 International License. Available online at www.turkarchotolaryngol.net
Cat-scratch disease (CSD) is one of the most common causes of infectious cervicofacial lymphadenopathies in children, adolescents, and young adults. With this case report, we highlight the wide spectrum of atypical manifestations of CSD in an elderly patient who presented not only with cervicofacial lymphadenopathies but also parotid enlargement, and Parinaud's oculoglandular syndrome which comprises granulomatous nonsuppurative conjunctivitis with adjacent ipsilateral preauricular lymphadenopathy. A high index of suspicion is needed to correctly diagnose and treat this clinical entity.

Keywords: Cat-scratch disease, cervicofacial lymphadenopathy, Parinaud's oculoglandular syndrome, parotid swelling

\section{Introduction}

Cat-scratch disease (CSD), is an infection typically caused by the microorganism Bartonella henselae (1). The cat flea is the most important vector of transmission of $B$. henselae, spreading the bacterium among cats who can then transmit it to humans by scratching or biting (1).

This infection is endemic in Europe, Africa, Australia, and Japan, and one of the most common causes of chronic cervicofacial lymphadenopathy in young adults and children (2).

The clinical manifestation of a $B$. henselae infection highly depends on the immune status of the patient. Immunocompetent patients usually present with typical CSD, which is initially characterized by a papule at the site of inoculation, followed by proximal regional lymphadenopathy that can last weeks to months (3). Atypical manifestation occurs in 5\% of the cases and may include Parinaud's oculoglandular syndrome (which comprises granulomatous nonsuppurative conjunctivitis with adjacent ipsilateral preauricular lymphadenopathy), neuroretinitis, encephalitis, osteomyelitis, endo- carditis, hepatosplenic lesions, and fever of unknown origin. In immunocompromised patients CSD may also manifest as bacteremia, bacillary angiomatosis and peliosis (3).

We report the case of an elderly female patient with cervical suppurative lymphadenitis characterized with parotid and ocular involvement, for which investigation revealed a CSD with atypical manifestations.

\section{Case Presentation}

A 66-year-old female patient presented to emergency department with facial and cervical swelling that had begun one week ago. She reported having been scratched in the left hand by her cat two weeks earlier. On physical examination she presented right-sided facial swelling, ipsilateral parotid mass palpation, enlarged and tender unilateral cervical lymph nodes, and ipsilateral red eye (Figure $1 \mathrm{a}, \mathrm{b}$ ). She also presented an excoriation on her left hand (Figure 1c). The remainder of the head and neck examination was unremarkable. She underwent a neck computed tomography which revealed necrotic cervical lymphadenopathies in the right levels I and 

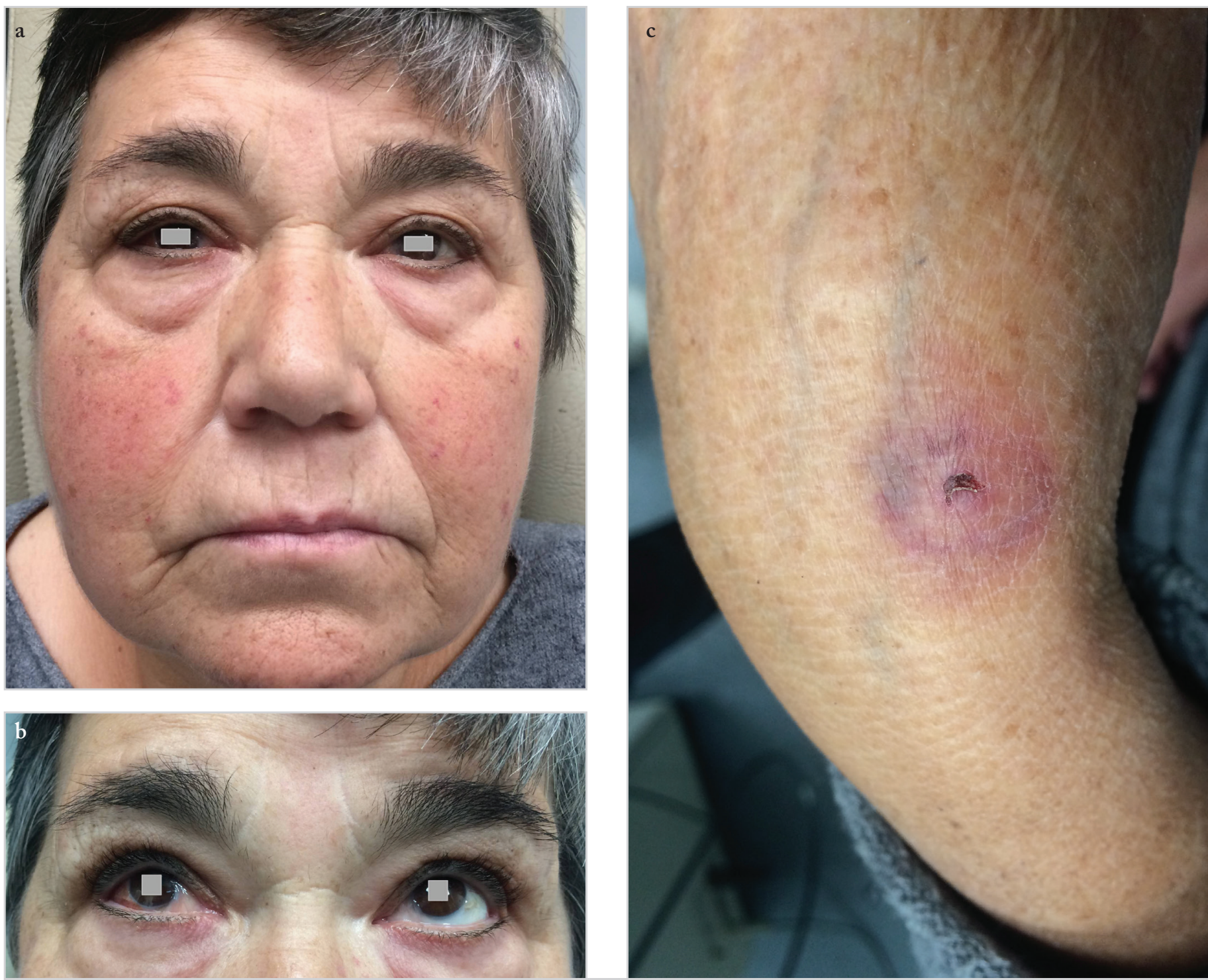

Figure 1. a-c. The patient presented right-sided facial swelling, ipsilateral parotid mass, enlarged and tender unilateral cervical lymph nodes, and ipsilateral red eye $(\mathrm{a}, \mathrm{b})$. An excoriation was visible on the left hand (c)

II, necrotic irregular nodules in the right parotid gland along with parotid enlargement (Figure $2 \mathrm{a}-\mathrm{c}$ ). Ophthalmologic examination confirmed the presence of right-sided follicular conjunctivitis and intermediate uveitis. Best-corrected visual acuity was $7 / 10$ in the right eye and 9/10 in the left eye, with an intraocular pressure of $12 \mathrm{mmHg}$ in the right eye and $14 \mathrm{mmHg}$ in the left eye. Slit lamp biomicroscopy revealed follicular conjunctivitis with mucous discharge and mild anterior vitritis without anterior segment reaction. Fundoscopy was unremarkable. Biopsy of the parotid gland revealed necrotizing granulomas with central stellate microabscesses. Serologic test (indirect immunofluorescence) was positive for $B$. henselae (immunoglobulin G 1/1280). Antibiotic therapy was begun (doxycycline, $100 \mathrm{mg}$ every 12 hours on the first day, followed by $100 \mathrm{mg} /$ day for 10 days). On follow-up, two months after treatment, the patient's parotid masses and cervical lymphadenopathies had completely resolved along with the ocular disease.

\section{Discussion}

In this case report, we highlight the wide spectrum of atypical manifestations of CSD, in the same patient presenting with not only cervicofacial lymphadenopathies but also parotid enlargement, and Parinaud's oculoglandular syndrome.

Ridder et al. (2) reported CSD to be one of the most common causes of lymphadenopathy in the head and neck region and Hamilton et al. (4) showed that the neck is, indeed, the site most commonly involved in CSD. On the other hand, parotid gland involvement is reported to be present in only $6 \%$ of the patients with CSD and usually associated with Parinaud's syndrome $(2,3,5,6)$.

CSD is one of the leading causes of benign chronic lymphadenopathy in children and young adults, whereas its occurrence in the elderly is very rare (7). Our patient, besides being elderly, also presented atypical features of CSD, which are reported to be more frequent in this age group (7). Ben-Ami et al. (7) studied the clinical features of CSD in 846 immunocompetent $\mathrm{pa}^{-}$ tients according to their age (elderly $\geq 60$ years vs nonelderly $\leq 60$ years). In their study, although atypical CSD was more common in the elderly group than in the nonelderly ( $32.7 \%$ vs. $13.6 \%)$, there were no cases of Parinaud's oculoglandular syndrome in 



Figure 2. a-c. Coronal (a,b) and axial (c) post contrast neck computed tomography revealed necrotic cervical lymphadenopathies in the right levels I and II, multiple necrotic irregular nodules in the right parotid gland along with parotid enlargement

the elderly age group, which makes our reported case even more exceptional (7).

Differential diagnosis includes not only benign reactive conditions, such as other causes of granulomatous disease (Tuberculosis, Syphilis, Lyme Disease, Brucellosis, Tularemia, Sporotrichosis, Chlamydia infection, Sarcoidosis, among others), but also malignant neoplasms $(2,8,9)$. Of particular importance, specifically considering the age group and the presence of atypical manifestations in our patient, is that malignancy was considered more prominently in the differential diagnosis of regional lymphadenopathy.

The indirect immunofluorescence serologic techniques are the gold standard for the detection of antibodies against $B$. henselae, with a sensitivity and specificity of $90 \%$ in immunocompetent patients $(3,9)$. Also, B. Henselae polymerase chain reaction hybridization or sequencing assay specimen provide high diagnostic sensitivity, however, these are only available in a few specialized centers. These laboratorial techniques, although not widely accessible, might avoid unnecessary invasive procedures or surgery for the diagnosis of CSD (9).

In spite of spontaneous recovery of CSD generally occurring within months to years, there is no data available regarding the benefits of specific antimicrobial therapy for immunocompetent patients with atypical presentations (10). Irrespective of these uncertainties, some authors have suggested that early treatment seems to shorten the duration of the disease $(9,11)$. Furthermore, without treatment, CSD can occasionally progress to severe life-threatening complications, particularly in the elderly population $(7,10)$. Therefore, in our case, antibiotic therapy was decided given the severe, painful and abscessed lymphadenopathies, and our patient evolved favorably after the introduction of this treatment.

The diagnosis of CSD, particularly in atypical cases, can easily be overlooked if the primary inoculation site is unapparent and if no history of cat exposure is elicited. Therefore, a high index of suspicion to correctly diagnose and treat this clinical entity is needed.

\section{Conclusion}

CSD should be considered in the differential diagnosis of suspicious lymphadenopathies of the cervicofacial region in patients of all age groups, and antibiotic therapy could be useful in $\mathrm{pa}^{-}$ tients with severe or atypical manifestations.

Informed Consent: Written informed consent was obtained from the patient who participated in this case.

Peer-review: Externally peer-reviewed.

Author Contributions: Concept - A.S.M., D.R.; Design - A.S.M.; Supervision - A.S.M.; Data Collection and/or Processing - A.S.M.; Analysis and/or Interpretation - A.S.M.; Literature Search - A.S.M.; Writing - A.S.M.; Critical Reviews - A.S.M., D.R., A.F.L.

Conflict of Interest: The authors have no conflicts of interest to declare.

Financial Disclosure: The authors declared that this study has received no financial support.

\section{References}

1. Nelson CA, Moore AR, Perea AE, Mead PS. Cat scratch disease: U.S. clinicians' experience and knowledge. Zoonoses Public Health 2018; 65: 67-73. [Crossref]

2. Ridder GJ, Boedeker CC, Technau-Ihling K, Grunow R, Sander A. Role of cat-scratch disease in lymphadenopathy in the head and neck. Clin Infect Dis 2002; 35: 643-9. [Crossref]

3. Ridder GJ, Boedeker CC, Technau-Ihling K, Sander A. Catscratch disease: otolaryngologic manifestations and management. Otolaryngol Head Neck Surg 2005; 132: 353-8. [Crossref]

4. Hamilton DH, Zangwill KM, Hadler JL, Cartter ML. Cat-scratch disease-Connecticut, 1992-1993. J Infect 1995; 172: 570-3. [Crossref]

5. Ben Slama L,Hasni W, Royer B. [Cat-scratch disease localisation in the parotid gland]. Rev Stomatol Chir 2008; 109: 183-6. [Crossref]

6. García García JC, Núñez Fernández MJ, Portillo Barrio A, Oteo Revuelta JA. Cat-scratch disease presenting as parotid gland ab- 
scess and aseptic meningitis. Enferm Infecc Microbiol Clin 2017; 35: 58-9. [Crossref]

7. Ben-Ami R, Ephros M, Avidor B, Katchman E, Varon M, Leibowitz $\mathrm{C}$, et al. Cat-scratch disease in elderly patients. Clin Infect Dis 2005; 41: 969-74. [Crossref]

8. Lamps LW, Scott MA. Cat-scratch disease: historic, clinical, and pathologic perspectives. Am J Clin Pathol 2004; 121: S7180. [Crossref]
9. Galindo-Bocero J, Sánchez-García S, Álvarez-Coronado M, Rozas-Reyes P. Parinaud's oculoglandular syndrome: a case report. Arch Soc Esp Oftalmol. 2017; 92: 37-9. [Crossref]

10. Angelakis E, Raoult D. Pathogenicity and treatment of Bartonella infections. Int J Antimicrob Agents. 2014; 44: 16-25. [Crossref]

11. Reed JB, Scales DK, Wong MT, Lattuada CP, Dolan MJ, Schwab IR. Bartonella henselae neuroretinitis in cat scratch disease. Diagnosis, management, and sequelae. Ophthalmology 1998; 105: 459-66. [Crossref] 